\title{
Die Medizin unter dem Diktat des Zeitgeistes?
}

Annina Hess-Cabalzar

Korrespondenz:

Annina Hess-Cabalzar Leitung Psychotherapie PsyA®T Mitglied der Spitalleitung Spital Affoltern am Albis annina.hess@spitalaffoltern.ch www.spitalaffoltern.ch www.menschenmedizin.ch
Von welchem Geist wird in Spitälern und Kliniken die Beziehung zwischen Ärzteschaft, Pflegenden, anderen beteiligte Professionellen und Patienten getragen? Handelt es sich um ein partnerschaftliches Verhältnis oder um ein Abhängigkeitsverhältnis, das zwischen Macht und Ohnmacht pendelt? Wer entscheidet darüber, wie dieses Verhältnis gestaltet wird? Kann überhaupt noch entschieden werden, oder haben wir einen Zustand wie in Goethes «Zauberlehrling», wo es heisst:

«Herr, die Not ist gross!

Die ich rief, die Geister,

Werd' ich nun nicht los.»

Die Frage sei erlaubt: Weshalb raufen wir alle, die in der Behandlung und Begleitung von Patientinnen und Patienten tätig sind, uns nicht interdisziplinär zusammen und formieren uns zu einer unüberhörbaren, kraftvollen Stimme, die Bund und Kantone unmissverständlich auffordert, bei der Bevölkerung zu evaluieren, wofür sie ihr durchaus reichlich vorhandenes Geld ausgeben will?

Wir Behandelnde aller Disziplinen und medizinischer Bereiche lassen uns über unsere Schmerzgrenze hinaus quetschen und auf immer enger werdende Blickwinkel deprimieren. Wir sollten - einem industriellen Produktionsbetrieb gleich - mit weniger Zeit und weniger Geld noch mehr Qualität «liefern» und die Patienten und Patientinnen zunehmend auf marktwirtschaftliche Messgrössen reduzieren.

Wollen wir trotz aller Umstrukturierungsmassnahmen patientenorientierte, würdige Behandlungen und Begleitungen anbieten, bleibt für den homo politicus in uns ganz einfach keine Zeit. Allein, was geschieht an den Bürotischen ohne die dezidierten Stimmen aus den Behandlungsteams? Es darf doch nicht sein - oder doch? - dass die Ermüdung und Resignation sich schon so weit eingeschlichen hat, dass die existenziellen Fragen, die einem Heilsystem zugrunde liegen, unter nicht zu evaluierenden Datenbergen ersticken und unsere Kraft zur energischen Stellungnahme von den entmutigenden «Da-ist-nichts-mehr-zu-machen»Geistern gelähmt wird.

Welcher Zeitgeist diktiert uns eigentlich? War da nicht einmal das Anliegen der Aufklärung, den Menschen von Autoritäten zu befreien? War da nicht die Idee, dass er mit freiem Sinn die Welt gestalten möge? Es kann nicht im Sinn des freien Menschen sein, dass sein höchstes Gut, die Gesundheit, in Wettbewerb und Konkurrenz geschickt wird. Vielmehr gilt: Die wich-

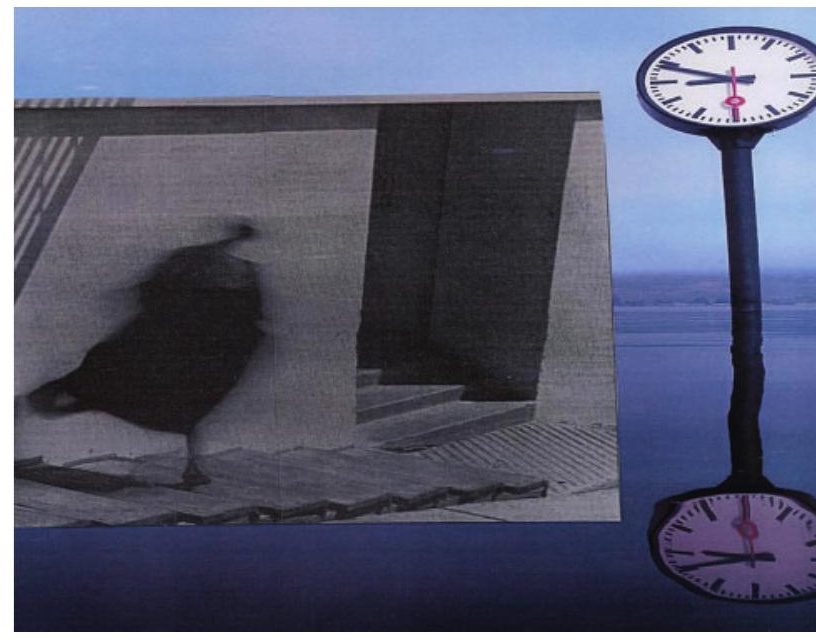

Eine menschenorientierte Medizin reduziert Patienten nicht auf marktwirtschaftliche Messgrössen.

tigsten Grundlagen einer humanistischen Medizin sind sinnvolle Behandlungsketten, Respekt für die jeweiligen Aufgaben der Haus-, Spital- und Fachärzteschaft, und dies gilt analog in allen anderen Betreuungsdisziplinen.

Die Zeit ist reif für das egalitäre, multiprofessionelle Zusammenspiel in Behandlung und Begleitung, sowie im politischen Vorgehen zum Wohle einer Heilkunst, die uns auch deshalb begeistert, weil sie freiwillig menschliche und materielle Grenzen akzeptiert. Und die Zeit ist reif, dass sich die einzelnen medizinischen Disziplinen zusammentun und auch politisch engagieren für eine menschenorientierte Medizin. Eine Art und Weise der Medizin, an die wir uns gegebenenfalls im Vertrauen wenden dürfen.

Wie heisst es im «Zauberlehrling» auch:

«In die Ecke / Besen! Besen! / Seid's gewesen! Denn als Geister / Ruft euch nur, zu seinem Zwecke Erst hervor der alte Meister.»

Diesen Worten ist nichts beizufügen.

\section{Symposium «Wa(h)re Medizin»}

Das Spital organisiert in Affoltern am 6. Nov. 2010 unter dem Titel «Wa(h)re Medizin Heilkunst und Gesundheitsmarkt» ein Symposium, das sich vertieft mit den in diesem Beitrag angesprochenen Fragen auseinandersetzt. Informationen dazu und Anmeldung unter www.spitalaffoltern.ch 